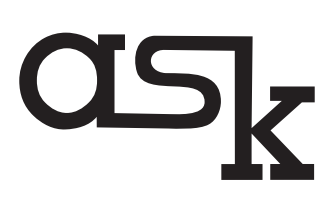

Research \& Methods

ISSN 1234-9224, e-ISSN 2544-0799

Vol. 27 (1, 2018): 41-59

The Ohio State University Libraries

Columbus, Ohio, USA

Institute of Philosophy and Sociology

Polish Academy of Sciences, Warsaw, Poland

www.askresearchandmethods.org

DOI: 10.18061/ask.v27i1.0003

\title{
Testing Question Order Effects of Self-perception of Risk Propensity on Simple Lottery Choices as Measures of the Actual Risk Propensity
}

\section{Jakub Golik}

Faculty of Management and Economics, Gdańsk University of Technology, Gdańsk

\begin{abstract}
Uncertainty together with the necessity of making choices inevitably results in risky decisions. For many years now, scientists have been studying notions connected with risk such as risk management, risk perception or risk propensity. While many sophisticated methods regarding measurement of risk propensity have been developed so far, it seems that little attention has been paid to checking whether they are not inherently flawed.

The main goal of this article is to check with a simple preliminary study whether questionnaire based methods of risk propensity assessment are not susceptible to question order effects. The research is focused on respondents' answers to simple lottery choices as measures of their risk propensity. However, what would happen if the respondents were first asked how they perceive their own risk propensity? In order to answer this query a few questions designed to measure risk propensity and self-perception of risk propensity have been interspersed in a questionnaire of another research project. Furthermore, as an additional output of the study, the correlation has been checked between self-perception of risk propensity and the actual assessment of risk propensity based on the questions used.

The results of the study show that question order effects are partially present in the setting described. Some conclusions and recommendations for further research are made based on the results. Finally, it can be concluded from the research that simple self-perception of risk propensity was significantly correlated with measures of actual risk propensity used.
\end{abstract}

Keywords: order effects, questions order, risk propensity, risk perception, simple lottery 


\section{INTRODUCTION}

Uncertainty together with the necessity of making choices inevitably results in making risky decisions. For many years now, scientists have been studying notions connected with risk such as risk management, risk perception or risk propensity. Due to the complexity of the subject and problems with comparability between multiple disciplines, dozens of models and measurement methods regarding risk propensity have been developed (Harrison et al. 2005). Hence, the leading research approaches differ according to the discipline; whether it is psychology, finance, economics, behavioural economics or mathematics. However, recent interest of scientists seems to be focused on the more interdisciplinary question of whether there exists a general risk propensity which could be applied to any research field (Tyszka and Domurat 2004) (Meertens and Lion 2008) (Hung and Tangpong 2010).

While many sophisticated methods regarding measurement of risk propensity have been developed so far, it seems that little attention has been paid to checking whether they are not inherently flawed. The main goal of this article is to check with a simple preliminary study whether questionnaire based methods of risk propensity assessment are not susceptible to question order effects. The research is focused on respondents' answers to simple lottery choices as measures of their risk propensity. However, what would happen if the respondents were first asked how they perceive their own risk propensity? In order to answer this query a few questions designed to measure risk propensity and self-perception of risk propensity have been interspersed in a questionnaire of another research project. Furthermore, as an additional output of the study, the correlation has been checked between self-perception of risk propensity and the actual assessment of risk propensity based on the questions used.

\section{OVERVIEW OF THE MOST NOTABLE RESEARCH REGARDING RISK PROPENSITY AND ORDER EFFECTS}

Prior to discussing details of the study, necessary definitions will be explained and a brief overview of the most notable research regarding risk propensity will be presented. The reason for this is to highlight the current trends in research and suggest further reading regarding subjects and notions connected with risk propensity not included or going beyond the scope of this article.

Following the definition of risk propensity by Sitkin and Weingart (1995), it is an individual's current tendency to take or avoid risk. An inseparable notion from risk propensity is risk perception defined as an individual's assessment of how risky a particular situation is in terms of probability of occurrence, controllability 
of the uncertainty and confidence in own estimates of the above mentioned factors (Baird and Thomas 1985) (Bettman 1973).

As both definitions refer to an individual and his or her feelings and/or assessments, this might suggest problems with interpersonal comparability similar to problems recognised by Pareto regarding the concept of utility (Golik 2016). Moreover, the word "current" indicates potential changes over time which question whether risk propensity can be treated as a stable individual attribute, see (Sitkin and Weingart 1995). However, for the purpose of this study the given definitions suffice and do not require further discussion.

While measuring risk propensity, two major approaches should be distinguished. The first is to study the choices made in either real or hypothetical games or scenarios, and the second is to ask respondents questions about risky situations or their personality traits related to risk (Coppola 2014). Measures which are most commonly associated with risk propensity are behavioural measures. In these measures, respondents are usually asked to make a choice between particular options, and they directly experience the outcome (Mishra and Lalumière 2011). An example of such a measure can be a choice between two alternative simple lotteries where both of them have exactly the same mean expected value but one of them has higher outcome variance. This type of measurement is preferred by researchers doing experiments due to the fact that in such cases they can easily measure the difference in risk-propensity caused by experimental manipulation (Mishra and Lalumière 2011).

The second type of measure are personality measures. Self-report measures of personality traits associated with risk such as impulsivity, sensation-seeking or low self-control seem to be a good predictor of real-world risk taking (Mishra and Lalumière 2011). Mishra and Lalumière (2011) have conducted research regarding associations between those two types of measures of risk propensity. Research on a similar topic has also been carried out by (Aklin et al. 2005).

A comprehensive and systematic review of instruments that measure risk propensity has been made by (Harrison et al. 2005). From 3546 articles the authors have identified 14 instruments - eight of them measured risk propensity and the remaining six concerned personality traits associated with risk propensity. All of the instruments have been described in detail specifying i.a. authors, risk domain, measurement method and also supported with examples of application.

Two of the most popular personality measures seem to be Zuckerman's Sensation-Seeking Scale (SSS-V) and the Domain-Specific Risk Taking Scale (DOSPERT) developed by (Weber and Blais 2006). On the basis of a Likert scale, the former requires 40 choices to be made between questions like e.g. "A sensible person avoids activities that are dangerous" and "I sometimes like to do things that are a little frightening" (Zuckerman 1994), the latter however, is a type of self- 
report measure of likelihood of engaging in different risky behaviours i.e. financial (investing and gambling); health/safety; recreational; ethical and social. An example of DOSPERT scale application can be a recent paper by Michela Coppola (2014) in which she compares different measures in socio-economic surveys.

When it comes to behavioural measures of risk propensity, examples of such measures could be the Choice Task (CT) and Balloon Analogue Risk Task (BART). To give an example: BART is a computer simulated exercise in which the participant sees a depiction of a balloon on a computer screen and has an option to press the button "pump". The instruction is given that each pressing of the button inflates the balloon and gives the participant $0,05 \$$. However, the balloon might pop after even one pump. After the balloon pops the money from the particular balloon is cleared and the participant moves to the next balloon out of 10 in total (this is an example of a BART test based on (Lejuez et al. 2002)).

Various measures of risk propensity are naturally applied in a wide variety of fields. For instance, (Sharma et al. 2009) studied consumers' risk propensity in the field of marketing using a field-specific construct of Consumer Risk Propensity (CRP) as their theoretical basis. The work by Zheng and Prislin (2012) was aimed at investigating the risk propensity of students of entrepreneurship and of subjects other than entrepreneurship by conducting a computer-facilitated game experiment with a behavioural measure and two moderators (i.e. evaluation period and information relevance). In another work by Mishra and Lalumière (2011) the subject of investigation was gambling as a form of risk-taking analysed with the use of behavioural measures. Finally, one of the recent studies was focused on risk propensity within the military, which suggested that some demographic factors might influence individual inclinations towards risky behaviour (Börjesson, Österberg, and Enander 2015).

The last mentioned research by (Börjesson et al. 2015) indicates one of the issues currently investigated regarding measurement of risk propensity in the literature - differences stemming from socio-demographic factors. The work by Tyszka and Domurat (2004) seems to confirm that concern. Furthermore, their research shows that the measurement of an individual's propensity for risk measured using several different instruments appears to be incohesive and hence, sometimes inconclusive. The problem of low consistency while trying to classify an individual by risk propensity with the use of several different methods had already been noticed before in classic works by (Slovic 1964) and (Jackson, Hourany, and Vidmar 1972).

Despite the efforts of research on general risk propensity (Meertens and Lion 2008), (Hung and Tangpong 2010), there still seems to be some doubt regarding the validity and consistency of the results of existing methods of measurement. One such doubt, which to the author's best knowledge has not been studied extensively, 
concerns question order effects which might potentially affect the results of some question-based methods of risk propensity assessment.

The order effect is a well-documented psychological phenomenon where the order of questions asked, for example in a questionnaire, might influence a respondent's answer (Strack 1992) (Schwarz and Hippler 1995). For example, question B might be answered differently if it is asked before or after question A. Whether such a case has an influence on the respondent depends on two factors. Firstly, "if the respondent is aware of the preceding question at the time of answering a subsequent one" and secondly if the respondents can notice the relation of the two questions (Strack 1992). Hence, if the individual is aware of either of these two factors, this might influence his or her reaction and even make him or her "counteract" this effect (consciously or unconsciously).

\section{RESEARCH PROBLEMS, RESEARCH HYPOTHESES, METHODOLOGY AND RESEARCH SAMPLE}

The research is focused on respondents' answers to simple lottery questions (choices) (further referred to as SL1 and SL2) as measures of their risk propensity. However, the author poses the question of what would happen if the respondents were first asked how they perceive their own risk propensity (i.e. self-perception of risk propensity). Self-perception of risk propensity in this paper refers to a respondent's subjective individual assessment of his or her risk propensity in comparison to other people.

In other words, would answering the question about their self-perception of risk propensity (further referred to as SPRP) first affect the answers to the subsequent simple lottery choices and hence change the actual risk propensity assessment? Following the logic presented by Strack (1992), the author aims to check whether simple lottery questions (SL1 and SL2) are answered differently if they are asked prior to or subsequent to the SPRP question.

Furthermore, it seems to be worth checking whether the answers to the SPRP question itself are similar regardless of its position in a questionnaire. Intuition would suggest that they should. However, other possible outcomes of the study ought to be taken into account. For instance, one possible scenario is that answers to the SPRP question are similar regardless of its position (the order of this question in a questionnaire can still affect the answers to SL1 and SL2) while another outcome could be that the answers differ significantly (which might be a sign for further investigation). As the SPRP question represents a type of selfreported data it should be used with caution.

As an additional output of the study, the correlation between SPRP and the actual assessment of risk propensity based on the questions used and the consistency 
of answers (defined later in the article) in both SL1 and SL2 questions has been checked. To the author's best knowledge, little has been done to investigate an individual's self-perception of risk propensity (as defined above) with regard to results acquired from risk propensity measurement.

Taking into account the reasoning presented above, the following research hypotheses have been made:

$\mathrm{H}_{1}$ : The order of the SPRP question affects the answers given to the SL1 and SL2 questions in a significant way. The question order effect is present.

$\mathrm{H}_{2}$ : The answers to the SPRP question do not depend on order of the SPRP question.

$\mathrm{H}_{3}$ : SPRP is positively correlated with the actual risk-propensity measurement (RPsum variable - defined later in the article)

In order to achieve the goals of the study and find answers to the research problems, several obstacles identified by previous researches had to be tackled. One of the problems with risk propensity measurement already mentioned is the influence of socio-demographic factors (Tyszka and Domurat 2004), something particularly important due to the fact that the research has been carried out with the use of quantitative methods. However, the problem has been minimised due to the homogeneity of the respondent group (all respondents were final year full-time students of the Faculty of Management and Economics of Gdańsk University of Technology).

Another serious problem concerning such research was indicated by Traczyk and Zaleskiewicz (2016) who stated that typical methods examining differences in risk propensity such as lotteries, dilemmas or questionnaires require explicit declaration of willingness to take risk, which might result in a biased answer. The bias might be caused by "the need for self-presentation or situational characteristics such as time pressure and cognitive constraints that lead to more spontaneous and automatic processing of risk-related information." (Traczyk and Zaleskiewicz 2016). As a result, respondents might give untrue answers driven by hidden motives or based on the expectations of others. In order to minimise these problems, the author decided to intersperse the questions in a questionnaire of another research project, the topic of which was clear and not directly related to risk propensity. Potential drawbacks caused by such an approach will be discussed at the end of the article.

Finally, the decision to intersperse questions in the questionnaire of another research project made it difficult to use any of the known risk propensity measures in full scope. As Coppola noticed by giving an example of a DOSPERT scale - 
"measures based on self-report require individuals to answer a large amount of items; this makes it impossible to include them in surveys with a focus which goes beyond the pure elicitation of risk attitudes." (Coppola 2014). Hence, the measure had to be very much simplified in order to attach it to another questionnaire and to adjust it to already existing questions.

Due to limited resources, this preliminary study consisted only of three questions: one regarding self-perception of risk propensity (SPRP) and the remaining two being an adapted version of classic questions by (Warneryd 1996). The question regarding self-perception of risk propensity was very similar in form to the seventh question of The Risk Propensity Scale developed by Meertens and Lion (2008). Due to the form of other questions in the external questionnaire, this question had to have the form of a five-level Likert scale. The question was constructed as follows (SPRP question): In comparison with other people, I assess my propensity (inclination, tendency) for undertaking risky actions as: with the following answers in ordinal scale: definitely lower; rather lower; neither lower, nor higher; rather higher; definitely higher. The two questions regarding risk propensity were simple lotteries adopted from (Warneryd 1996). One of them being a simple lottery with one guaranteed option and the other being a probabilistic option; and the second being a lottery with two probabilistic options with the same expected value but different variance. These were as follows. Simple Lottery 1 (further referred to as SL1): If you were to choose between the two of the following alternatives, which one would you choose? A. receiving 50 PLN (zloty) B. receiving 100 PLN (ztoty) with probability $1 / 2(50 \%)$ or receiving nothing $(0 P L N)$ with probability $1 / 2(50 \%)$; Simple Lottery 2 (further referred to as SL2): If you were to choose between the two of the following alternatives, which one would you choose? A. receiving 100 PLN (złoty) with probability $1 / 2(50 \%)$ or losing 100 PLN (-100 PLN) with probability $1 / 2$ (50\%) B. receiving 500 PLN (zloty) with probability $1 / 2$ (50\%) or losing 500 PLN (-500 PLN) with probability $1 / 2(50 \%)$;

All of the three (interspersed) questions looked the same as other questions of the questionnaire with respect to the font and style, and were more or less evenly spaced within the questionnaire (neither of them was ever put earlier than as the $6^{\text {th }}$ question of the questionnaire out of 24 in total). The 5 item Likert scale was chosen to be consistent with the rest of the questions which had this form.

The questions were attached to a questionnaire belonging to a SEAS Project (Survey on Entrepreneurial Attitudes of Students). The SEAS Project started in 2008 as a longitudinal study of students' entrepreneurship attitudes, their determinants and antecedents, combined with a career choice study, education process evaluation and other student-related issues. Questions in the SEAS questionnaire have been designed to measure or investigate i.a. students' entrepreneurial intentions, entrepreneurial self-efficacy, work experience, and the presence of entrepreneurs 
in the family. However, none of these questions is directly related to measuring risk-propensity nor its self-perception. The project is realised in the form of an annual quantitative study at the Faculty of Management and Economics of Gdańsk University of Technology in Poland (further referred to as FM\&E, GUT).

The research sample consisted of two groups of students of FM\&E, GUT from different courses (it is safe to assume that groups did not know each other and were not aware of the research conducted in the other group). Students of both groups were of a similar age, all of them were experienced students (i.e. students of the last year of their course) with a similar course programme. The first group (consisting of 102 students) received a questionnaire where the SPRP question was put before the SL1 and SL2 questions, whereas the second group (consisting of 91 students) received a questionnaire where the SPRP question was put after the SL1 and SL2 questions. In total 193 students filled in the questionnaires (both versions of question ordering). However, due to missing answers to some of the questions of interest, 99 questionnaires from the first group and 88 questionnaires from the second group were taken to the final analysis (total of 187 responses).

\section{DESCRIPTION OF VARIABLES AND STUDY RESULTS}

In order to perform the analysis six variables have been created. The first one denoted as "var1: Order" is related to the order of questions (whether the SPRP question was asked prior to the SL1 and SL2 questions or not). It is a variable using a nominal scale, namely, value "SPRP --> SL" represents the order in which the SPRP question is asked prior to both SL questions, and value "SL --> SPRP" represents the order in which the SPRP question is asked after both SL questions.

The second variable is a straightforward representation of answers to the selfperception of risk propensity question (SPRP question). It was named "var2: SPRP". This variable describes answers to the SPRP question with the use of an ordinal scale from 1 to 5: definitely lower (1); rather lower (2); neither lower, nor higher (3); rather higher (4); definitely higher (5) (a typical five-level Likert scale).

With regard to the simple lottery questions (SL1 and SL2) designed to measure risk propensity, it is crucial to notice that in both of them the first answer, A, is always considered a safer option (due to the guaranteed payoff and lower variance respectively), while the second answer, B, is considered more risky (by analogy - due to a probable instead of a guaranteed payoff and the higher variance respectively). The third and fourth variables denoted as "var3: SL1" and "var4: SL2" respectively use a nominal scale to represent answers " $A$ " and "B" to the SL questions. 
Another variable was called "var5: RPsum". With the use of an ordinal scale (ranging from 0 to 2 ) it assesses a respondent's risk propensity in a classical way similar to the summation method used with measures such as DOSPERT or SSS-V. The three possible outcomes of answering the SL1 and SL2 questions are: both safe answers (A and A), one safe and one risky answer (one answer A and one answer B regardless of the question), or both risky answers (B and B). Variable "var5: RPsum" describes these possibilities in the following way: 0 representing both safe answers, 1 representing one safe and one risky answer, 2 representing both risky answers. This variable can also be interpreted as a count of risky answers in the SL1 and SL2 questions. Hence, the higher the value of "var5: RPsum", the higher the risk-propensity of the respondent.

The last variable was called "var6: Consistency" with the use of a nominal scale and values " 0 " and " 1 ". Value " 0 " represents the situation when the respondent was not consistent in his or her choice of answers to SL1 and SL2 questions i.e. values in "var3: SL1" and "var4: SL2" were different. Value "1" represents the situation when the respondent was consistent with his or her choices to SL1 and SL2 questions i.e. values in "var3: SL1" and "var4: SL2" were the same ("A" and "A" or "B" and "B").

In order to make the reading more accessible, all the variables described above have been summarised in table 1 below with their abbreviations, scales and ranges.

Table 1. Description of variables, scales and ranges used

\begin{tabular}{|c|c|c|c|}
\hline \multicolumn{4}{|r|}{ Description of variables used } \\
\hline $\begin{array}{l}\text { variable } \\
\text { number }\end{array}$ & $\begin{array}{l}\text { variable } \\
\text { name }\end{array}$ & scale & description \\
\hline var1 & Order & nominal & $\begin{array}{l}\text { "SPRP --> SL", "SPRP --> SL" - order in which SPRP question } \\
\text { "SL --> SPRP" is asked prior to both SL questions (simple } \\
\text { lottery questions) } \\
\text { "SL --> SPRP" - order in which SPRP question } \\
\text { is asked after both SL questions (simple lottery } \\
\text { questions) }\end{array}$ \\
\hline var2 & SPRP & $\begin{array}{l}\text { ordinal (Likert) } \\
\text { scale }\end{array}$ & $\begin{array}{l}1 \text { to } 5 \text { answers to the self-perception of risk propensity } \\
\text { question }\end{array}$ \\
\hline var3 & SL1 & nominal & "A", "B" answer to SL1 question (simple lottery question 1) \\
\hline var4 & SL2 & nominal & $\begin{array}{l}\text { "A", "B" answer to SL2 question (simple lottery question } \\
\text { 2) }\end{array}$ \\
\hline var5 & RPsum & ordinal & 0 to 2 assessment of respondent's risk propensity \\
\hline var6 & Consistency & nominal & $\begin{array}{l}\text { "0", "1" "0" - not consistent answers in SL1 and SL2 } \\
\text { questions } \\
\text { "1" - consistent answers in SL1 and SL2 } \\
\text { questions }\end{array}$ \\
\hline
\end{tabular}


The handling of the data was based on the article by (Schuman et al. 1981). This classic work is recommended for further reading as it presents in a clear manner how to handle such data. Having collected, coded and cleared all the data, the particular contingency tables were created. These tables present the results in a clear way and make it possible to see the distributions of the variables. Table 2 and table 3 below contain the results obtained from the questionnaires. Table 2 represents answers to the self-perception of risk propensity question (SPRP) and the simple lottery question 1 (SL1) in both order groups (SPRP asked prior to SL questions "SPRP --> SL" and SPRP asked after SL questions "SL --> SPRP"). Similarly, Table 3 presents the answers given to the SPRP question and the simple lottery question 2 (SL2) in these groups. Furthermore, one of the advantages of contingency tables is the fact that they make it possible for the reader to recreate the original dataset in order to perform different calculations or to manually check the results of statistical tests.

Table 2. Contingency Tables with regard to SL1 (simple lottery question 1): SPRP vs SL1 question answers in both order groups (SPRP asked prior to SL questions "SPRP --> SL" and SPRP asked after SL questions "SL --> SPRP")

Contingency Tables with regard to SL1

\begin{tabular}{|c|c|c|c|c|c|c|c|}
\hline \multirow{2}{*}{ Order } & & \multirow{2}{*}{ SPRP } & & \multicolumn{2}{|c|}{ SL1 } & \multirow{2}{*}{\multicolumn{2}{|c|}{ Total }} \\
\hline & & & & $\mathrm{A}$ & $B$ & & \\
\hline \multirow{9}{*}{\multicolumn{2}{|c|}{$\overline{\text { SPRP --> SL }}$}} & 1 & Observed & 1 & 0 & 1 & $\%$ of total \\
\hline & & & $\%$ of total & $1.0 \%$ & $0.0 \%$ & & $1.0 \%$ \\
\hline & & 2 & Observed & 9 & 5 & 14 & $\%$ of total \\
\hline & & & $\%$ of total & $9.1 \%$ & $5.1 \%$ & & $14.2 \%$ \\
\hline & & 3 & Observed & 17 & 23 & 40 & $\%$ of total \\
\hline & & & $\%$ of total & $17.2 \%$ & $23.2 \%$ & & $40.4 \%$ \\
\hline & & 4 & Observed & 14 & 25 & 39 & $\%$ of total \\
\hline & & & $\%$ of total & $14.1 \%$ & $25.3 \%$ & & $39.4 \%$ \\
\hline & & 5 & Observed & 1 & 4 & 5 & $\%$ of total \\
\hline \multirow[t]{3}{*}{ Gamma $=0.339$} & & & $\%$ of total & $1.0 \%$ & $4.0 \%$ & & $5.0 \%$ \\
\hline & Total & & Observed & 42 & 57 & 99 & $\%$ of total \\
\hline & & & $\%$ of total & $42.4 \%$ & $57.6 \%$ & & $100 \%$ \\
\hline \multirow{2}{*}{\multicolumn{2}{|c|}{ SL --> SPRP }} & 1 & Observed & 1 & 0 & 1 & $\%$ of total \\
\hline & & & $\%$ of total & $1.1 \%$ & $0.0 \%$ & & $1.1 \%$ \\
\hline
\end{tabular}




\begin{tabular}{|c|c|c|c|c|c|c|c|}
\hline & & 2 & Observed & 17 & 4 & 21 & $\%$ of total \\
\hline & & & $\%$ of total & $19.3 \%$ & $4.5 \%$ & & $23.8 \%$ \\
\hline & & 3 & Observed & 22 & 12 & 34 & $\%$ of total \\
\hline & & & $\%$ of total & $25.0 \%$ & $13.6 \%$ & & $38.6 \%$ \\
\hline & & 4 & Observed & 10 & 18 & 28 & $\%$ of total \\
\hline & & & $\%$ of total & $11.4 \%$ & $20.5 \%$ & & $31.9 \%$ \\
\hline & & 5 & Observed & 2 & 2 & 4 & $\%$ of total \\
\hline Gamma $=0.534$ & & & $\%$ of total & $2.3 \%$ & $2.3 \%$ & & $4.6 \%$ \\
\hline & Total & & Observed & 52 & 36 & 88 & $\%$ of total \\
\hline & & & $\%$ of total & $59.1 \%$ & $40.9 \%$ & & $100 \%$ \\
\hline Total & & 1 & Observed & 2 & 0 & 2 & $\%$ of total \\
\hline & & & $\%$ of total & $1.1 \%$ & $0.0 \%$ & & $1.1 \%$ \\
\hline & & 2 & Observed & 26 & 9 & 35 & $\%$ of total \\
\hline & & & $\%$ of total & $13.9 \%$ & $4.8 \%$ & & $18.7 \%$ \\
\hline & & 3 & Observed & 39 & 35 & 74 & $\%$ of total \\
\hline & & & $\%$ of total & $20.9 \%$ & $18.7 \%$ & & $39.6 \%$ \\
\hline & & 4 & Observed & 24 & 43 & 67 & $\%$ of total \\
\hline & & & $\%$ of total & $12.8 \%$ & $23.0 \%$ & & $35.8 \%$ \\
\hline & & 5 & Observed & 3 & 6 & 9 & $\%$ of total \\
\hline & & & $\%$ of total & $1.6 \%$ & $3.2 \%$ & & $4.8 \%$ \\
\hline & Total & & Observed & 94 & 93 & 187 & $\%$ of total \\
\hline & & & $\%$ of total & $50.3 \%$ & $49.7 \%$ & & $100 \%$ \\
\hline
\end{tabular}

Table 3. Contingency Tables with regard to SL2 (simple lottery question 2): SPRP vs SL2 question answers in both order groups (SPRP asked prior to SL questions "SPRP --> SL" and SPRP asked after SL questions "SL --> SPRP")

Contingency Tables with regard to SL2

\begin{tabular}{|c|c|c|c|c|c|c|}
\hline \multirow{2}{*}{ Order } & \multirow{2}{*}{ SPRP } & & \multicolumn{2}{|c|}{ SL2 } & \multirow{2}{*}{\multicolumn{2}{|c|}{ Total }} \\
\hline & & & A & $\mathrm{B}$ & & \\
\hline \multirow[t]{6}{*}{ SPRP --> SL } & 1 & Observed & 0 & 1 & 1 & $\%$ of total \\
\hline & & $\%$ of total & $0.0 \%$ & $1.0 \%$ & & $1.0 \%$ \\
\hline & 2 & Observed & 11 & 3 & 14 & $\%$ of total \\
\hline & & $\%$ of total & $11.1 \%$ & $3.0 \%$ & & $14.1 \%$ \\
\hline & 3 & Observed & 22 & 18 & 40 & $\%$ of total \\
\hline & & $\%$ of total & $22.2 \%$ & $18.2 \%$ & & $40.4 \%$ \\
\hline
\end{tabular}




\begin{tabular}{|c|c|c|c|c|c|c|}
\hline & 4 & Observed & 16 & 23 & 39 & $\%$ of total \\
\hline & & $\%$ of total & $16.2 \%$ & $23.2 \%$ & & $39.4 \%$ \\
\hline & 5 & Observed & 1 & 4 & 5 & $\%$ of total \\
\hline Gamma $=0.398$ & & $\%$ of total & $1.0 \%$ & $4.0 \%$ & & $5.0 \%$ \\
\hline & Total & Observed & 50 & 49 & 99 & $\%$ of total \\
\hline & & $\%$ of total & $50.5 \%$ & $49.5 \%$ & & $100 \%$ \\
\hline SL --> SPRP & 1 & Observed & 1 & 0 & 1 & $\%$ of total \\
\hline & & $\%$ of total & $1.1 \%$ & $0.0 \%$ & & $1.1 \%$ \\
\hline & 2 & Observed & 10 & 11 & 21 & $\%$ of total \\
\hline & & $\%$ of total & $11.4 \%$ & $12.5 \%$ & & $23.9 \%$ \\
\hline & 3 & Observed & 17 & 17 & 34 & $\%$ of total \\
\hline & & $\%$ of total & $19.3 \%$ & $19.3 \%$ & & $38.6 \%$ \\
\hline & 4 & Observed & 11 & 17 & 28 & $\%$ of total \\
\hline & & $\%$ of total & $12.5 \%$ & $19.3 \%$ & & $31.8 \%$ \\
\hline & 5 & Observed & 1 & 3 & 4 & $\%$ of total \\
\hline Gamma $=0.189$ & & $\%$ of total & $1.1 \%$ & $3.4 \%$ & & $4.5 \%$ \\
\hline & Total & Observed & 40 & 48 & 88 & $\%$ of total \\
\hline & & $\%$ of total & $45.5 \%$ & $54.5 \%$ & & $100 \%$ \\
\hline Total & 1 & Observed & 1 & 1 & 2 & $\%$ of total \\
\hline & & $\%$ of total & $0.5 \%$ & $0.5 \%$ & & $1.0 \%$ \\
\hline & 2 & Observed & 21 & 14 & 35 & $\%$ of total \\
\hline & & $\%$ of total & $11.2 \%$ & $7.5 \%$ & & $18.7 \%$ \\
\hline & 3 & Observed & 39 & 35 & 74 & $\%$ of total \\
\hline & & $\%$ of total & $20.9 \%$ & $18.7 \%$ & & $39.6 \%$ \\
\hline & 4 & Observed & 27 & 40 & 67 & $\%$ of total \\
\hline & & $\%$ of total & $14.4 \%$ & $21.4 \%$ & & $35.8 \%$ \\
\hline & 5 & Observed & 2 & 7 & 9 & $\%$ of total \\
\hline & & $\%$ of total & $1.1 \%$ & $3.7 \%$ & & $4.8 \%$ \\
\hline & Total & Observed & 90 & 97 & 187 & $\%$ of total \\
\hline & & $\%$ of total & $48.1 \%$ & $51.9 \%$ & & $100 \%$ \\
\hline
\end{tabular}

In order to address $\mathrm{H}_{1}$ the marginals (i.e. total percentages at the bottom of answer "A" and answer "B" columns in appropriate parts of table 2 and table 3) should be compared. By comparing the marginals of answers to SL1 and SL2 in both orders of questions ("SPRP --> SL" and "SL --> SPRP") one may anticipate the question 
order effect. To check if the question order effect is present and to test the $\mathrm{H}_{1}$, the appropriate $\chi^{2}$ tests were performed and presented in table 4 and table 5 below.

Table 4. SL1 marginals by order $-x^{2}$ Tests

SL1 marginals by order $-\mathrm{X}^{2}$ Tests

\begin{tabular}{cccc}
\hline & Value & df & $p$ \\
\hline$X^{2}$ & 5.18 & 1 & 0.023 \\
$N$ & 187 & & \\
\hline
\end{tabular}

Table 5. SL2 marginals by order $-\chi^{2}$ Tests

SL2 marginals by order $-\chi^{2}$ Tests

\begin{tabular}{cccc}
\hline & Value & $\mathrm{df}$ & $\mathrm{p}$ \\
\hline $\mathrm{X}^{2}$ & 0.476 & 1 & 0.490 \\
$\mathrm{~N}$ & 187 & & \\
\hline
\end{tabular}

Interestingly, the tests show a significant order effect in the case of SL1 - see table $4\left(\chi^{2}=5,18, \mathrm{df}=1, \mathrm{p}<0,05\right)$ and no significant order effect $\left(\chi^{2}=0,476\right)$ for SL2 - see table 5 . Hence, $\mathrm{H}_{1}$ is only partially confirmed. The fact that choices in the SL2 question were unaffected by the preceding SPRP question might be the result of a mixture of several factors. The core difference between the SL1 and SL2 questions is that SL1 offers a guaranteed payoff while SL2 does not. This naturally raises the question whether some Prospect Theory (Tversky and Kahneman 1992) effects are present. As SL2 involves gain and loss, the loss of 500 PLN for students could have been perceived as "more significant" than the potential gain of 500 PLN. If a student cannot afford the loss of 500 PLN, he or she will most likely try to avoid taking part in such a lottery or, when asked, tend to select option A (the safer one). Hence, in the view of Prospect Theory, students should make fewer risky choices in SL2 given that potential losses are much larger. However, the percentages of risky choices (answers B) in both SL1 and SL2 questions are about the same - see last row "Total" in table 2 and table 3.

Regrettably, from the available data it is impossible to conclude whether the above mentioned factors had an influence over the SL2 choices, or to rule out the presence of any other potential effects. Furthermore, the results might have also been affected by uncontrolled differences between the groups.

When it comes to $\mathrm{H}_{2}$ - as anticipated, the answers to the SPRP question do not differ significantly with regard to question order. This can be observed by 
comparing marginals in appropriate parts of the contingency tables and by checking the $\chi^{2}$ test presented in table 6 below.

Table 6. SPRP marginals by order $-x^{2}$ Tests

\begin{tabular}{lcccc}
\multicolumn{3}{l}{ SPRP marginals by order $-X^{2}$ Tests } \\
\hline & Value & df & $p$ \\
\hline$X^{2}$ & 3.170 & 4 & 0.530 & \\
$\mathrm{~N}$ & 187 & & & \\
\hline
\end{tabular}

This result might be explained by analysing the structure of all questions of interest. Due to the fact that the SPRP question is more general than the two other simple lottery questions (being of a more specific nature) the answers to SPRP should not differ significantly regardless of its position in a questionnaire. For further explanation of this reasoning please refer to (Schuman, Presser, and Ludwig 1981).

The third hypothesis $\mathrm{H}_{3}$ was tested by making a correlation matrix and calculating the Spearman rank-order correlation coefficient (due to the fact that both variables SPRP and RPsum use an ordinal scale). Please note that the alternative hypothesis was "There is a positive correlation". SPRP and RPsum are positively correlated. The result is presented in table 7 below. Such a result indicates that there is a positive correlation between students' assessment of their risk-propensity and the actual result of risk-propensity derived from the simple measure of RPsum. Although the result regarding $\mathrm{H}_{3}$ might seem obvious, it is important to realise that self-reported data such as from the SPRP question often yield unexpected results (Van de Mortel 2008). Furthermore, the measure of selfperception of risk-propensity used was of a very simple nature (single item) and yet it turned out to be positively correlated with risk-propensity assessment.

Table 7. Spearman rank-order correlation coefficient (var2: SPRP \& var5: RPsum) - self-perception of risk propensity and assessment of respondent's risk propensity

Spearman rank-order correlation coefficient (var2: SPRP \& var5: RPsum)

\begin{tabular}{lcc}
\hline & RPsum \\
\hline SPRP & Spearman's rho & $0.314^{* * *}$ \\
& p-value & $<.001$ \\
\hline
\end{tabular}

Note. $\mathrm{H}_{\mathrm{a}}$ is positive correlation

Note. ${ }^{*} p<.05,{ }^{* *} p<.01,{ }^{* * *} p<.001$, one-tailed 
The last variable Consistency showing whether respondents were consistent in their choices to the SL1 and SL2 questions (both safe or both risky answers) does not differ between the groups, as can be observed on the plot 1 below. Blue bars on the plot represent the number of respondents answering inconsistently (value " 0 ") and in a consistent manner (value "1) to simple lottery questions in the "SPRP --> SL" order group. Orange bars on the other hand represent answers of respondents in the other i.e. the "SL --> SPRP" order group.

Plot 1. Consistency of repondents' answers in both order groups ("SPRP --> SL" blue bars and "SL --> SPRP" - orange bars). Value "0" - inconsistent answers; value "1" consistent answers.

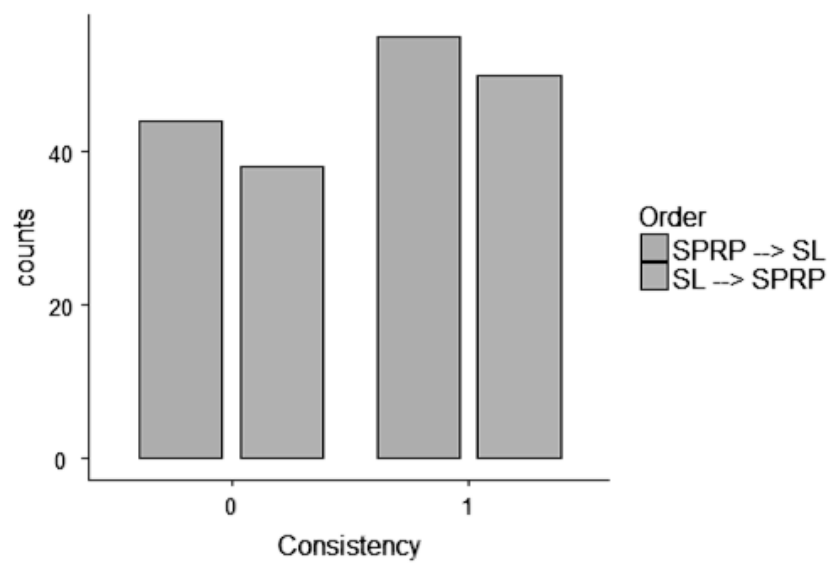

All of the computations in this article have been made with the use of jamovi software (jamovi project 2018).

\section{DISCUSSION, STUDY LIMITATIONS AND FURTHER RESEARCH AVENUES}

The results of the study show that question order effect affects SL1 - one of the questions designed to measure risk propensity, while there is no significant question order effect on SL2 in the described setting. Unfortunately, the reason for the absence of this effect with regard to the later question remains unknown. It might be partially explained by the Prospect Theory (Tversky and Kahneman 1992) as well as the suggestion that respondents read questions back and forth and have a possibility to go back to the previous questions to change the answer (Schwarz and Hippler, 1995), however, this aspect was not monitored and conclusions cannot be made about this. Furthermore, the outcome might just as well have 
been caused by uncontrolled differences between the groups. Nevertheless, this preliminary study highlights an important problem in research design which might not always be taken into account by researchers. It is advisable to at least take the possibility of question order effect occurrence into consideration while designing future research not only that regarding risk propensity.

The decision to intersperse questions in an external questionnaire had serious impact on the research. On one hand it possibly minimised the potential bias of respondents, which was a desired effect, however, on the other hand it seriously limited the study, restraining it from making more general conclusions due to the simplicity of the measures used. It would be advisable to replicate the study with a more extensive approach. The measures of risk propensity used were very much simplified and hence might not have been representative and conclusive enough. However, what is worth mentioning is the fact that the questions used had very low item nonresponse as in the research of (Coppola 2014).

It is important to emphasize that this was only a preliminary study and due to limited resources has its limitations. The study was performed in order to highlight a potential problem and encourage other researchers to replicate the study in better and more controlled environments. First of all, one might consider extending and properly randomising the groups, or even adding a control group to the study. Furthermore, another, more sophisticated method of risk propensity assessment could be used. Moreover, such research questions should be studied in different fields to limit the negative impact of order effect and make future questionnaire designs better.

Finally, it can be concluded from the research that simple self-perception of risk propensity was significantly correlated with the results derived from the measures of actual risk propensity used. Self-assessment of such notions as risk propensity might be an interesting field of research especially when studied together with various psychological effects as for instance framing effects or cognitive biases.

\section{ACKNOWLEDGMENT}

I would like to thank three anonymous reviewers for their thorough reviews and valuable remarks which helped me improve the article.

\section{REFERENCES}

Aklin, Will M., C. W. Lejuez, Michael J. Zvolensky, Chris W. Kahler, and Marya Gwadz. 2005. "Evaluation of Behavioral Measures of Risk Taking Propensity with Inner City Adolescents." Behaviour Research and Therapy 43(2):215-28. https:// doi.org/10.1016/j.brat.2003.12.007 
Baird, Inga Skromme and Howard Thomas. 1985. "Toward a Contingency Model of Strategic Risk Taking." The Academy of Management Review 10(2):230-43. https:// doi.org/10.5465/amr.1985.4278108

Bettman, James R. 1973. "Perceived Risk and Its Components: A Model and Empirical Test." Journal of Marketing Research 10(2):184. https://doi.org/10.2307/3149824

Börjesson, M., J. Österberg, and A. Enander. 2015. "Risk Propensity within the Military: A Study of Swedish Officers and Soldiers." Journal of Risk Research 18(1):55-68. https://doi.org/10.1080/13669877.2013.879489

Coppola, Michela. 2014. "Eliciting Risk-Preferences in Socio-Economic Surveys: How Do Different Measures Perform?" The Journal of Socio-Economics 48(February 2014):1-10. https://doi.org/10.1016/j.socec.2013.08.010

Densberger, Kathryn. 2014. "The Self-Efficacy and Risk-Propensity of Entrepreneurs." Journal of Enterprising Culture 22(4):437-62. https://doi.org/10.1142/S02184958 14500186

Golik, Jakub. 2016. "Expected Utility Hypothesis - Its Origin and Development." Gdańsk University of Technology. https://doi.org/10.13140/RG.2.2.13642.57288

Harrison, James D., Jane M. Young, Phyllis Butow, Glenn Salkeld, and Michael J. Solomon. 2005. "Is It Worth the Risk? A Systematic Review of Instruments That Measure Risk Propensity for Use in the Health Setting." Social Science \& Medicine 60(6):1385-96. https://doi.org/10.1016/j.socscimed.2004.07.006

Horcajo, Javier, Víctor J. Rubio, David Aguado, José Manuel Hernández, and M. Oliva Márquez. 2014. "Using the Implicit Association Test to Assess Risk Propensity SelfConcept: Analysis of Its Predictive Validity on a Risk-Taking Behaviour in a Natural Setting." European Journal of Personality 28(5):459-71. https://doi.org/10.1002/per.1925

Hung, Kuo-Ting and Chanchai Tangpong. 2010. "General Risk Propensity in Multifaceted Business Decisions: Scale Development*." Journal of Managerial Issues 22(1):7-8,88-106. Retrieved (http://search.proquest.com/docview/89213990?acco untid $=10297 \% 5 \mathrm{Cnhttp}: / /$ sfx.cranfield.ac.uk/cranfield?url_ver=Z39.88-2004\&rft_ val_fmt=info:ofi/fmt:kev:mtx:journal\&genre=article\&sid=ProQ:ProQ:abiglobal\&a title $=$ General + Risk + Propensity + in + Multifaceted + Business + ).

Jackson, Douglas N., Larry Hourany, and Neil J. Vidmar. 1972. "A Four-Dimensional Interpretation of Risk Taking1." Journal of Personality 40(3):483-501. https://doi. org/10.1111/j.1467-6494.1972.tb00075.x

jamovi project (2018). jamovi (Version 0.9) [Computer Software]. Retrieved from https://www.jamovi.org

Kaldana, Lina and Mitja Ruzzier. 2012. "Risk Propensity as Entrepreneurial Characteristic: The Case of Slovenian Students of Business and Economics Studies." International Journal of Management in Education 6(4):363. https://doi.org/10.1504/ IJMIE.2012.049347

Koloba, Habofanwe Andreas. 2014. "Innovation and Risk-Taking Propensity of Generation Y Students in South Africa." Mediterranean Journal of Social Sciences. https://doi.org/10.5901/mjss.2014.v5n21p19

Lejuez, C. W. et al. 2002. "Evaluation of a Behavioral Measure of Risk Taking: The Balloon Analogue Risk Task (BART)." Journal of Experimental Psychology: Applied 8(2):75-84. https://doi.org/10.1037/1076-898X.8.2.75 
Meertens, Ree M. and René Lion. 2008. "Measuring an Individual's Tendency to Take Risks: The Risk Propensity Scale." Journal of Applied Social Psychology 38(6):1506-20. https://doi.org/10.1111/j.1559-1816.2008.00357.x

Mishra, Sandeep and Martin L. Lalumière. 2011. "Individual Differences in RiskPropensity: Associations between Personality and Behavioral Measures of Risk." Personality and Individual Differences 50(6):869-73. https://doi.org/10.1016/j. paid.2010.11.037

Schuman, Howard, Stanley Presser, and Jacob Ludwig. 1981. "Context Effects on Survey Responses to Questions About Abortion. Author(s): Howard Schuman, Stanley Presser and Jacob Ludwig Source: The Public Opinion Quarterly, Vol. 45, No. 2 (Summer, 1981), P.” Oxford Journals 45(2):216-23.

Schwarz, Norbert and Hans-J. Hippler. 1995. "Subsequent Questions May Influence Answers to Preceding Questions in Mail Surveys." Public Opinion Quarterly 59(1):93-97. https://doi.org/10.1086/269460

Schwarz, Norbert, Hans-J. Hippler, and Elisabeth Noelle-Neumann. 1992. "A Cognitive Model of Response-Order Effects in Survey Measurement." Pp. 187-201 in Context Effects in Social and Psychological Research, edited by N. Schwarz and S. Sudman. New York, NY: Springer New York. https://doi.org/10.1007/978-1-4612-2848-6_13 Sharma, Dheeraj, Bruce L. Alford, Shahid N. Bhuian, and Lou E. Pelton. 2009. "A Higher-Order Model of Risk Propensity." Journal of Business Research 62(7):741-44. https://doi.org/10.1016/j.jbusres.2008.06.005

SITKIN, S. B. and L. R. WEINGART. 1995. "Determinants of Risky Decision-Making Behavior: A Test of the Mediating Role of Risk Perceptions and Propensity." Academy of Management Journal 38(6):1573-92. https://doi.org/10.5465/256844

Slovic, Paul. 1964. "Assessment of Risk Taking Behavior." Psychological Bulletin 61(3):220-33. https://doi.org/10.1037/h0043608

Strack, Fritz. 1992. "'Order Effects' in Survey Research: Activation and Information Functions of Preceding Questions." Pp. 23-34 in Context Effects in Social and Psychological Research. New York, NY: Springer New York. https:/doi. org/10.1007/978-1-4612-2848-6 3

Tourangeau, R., Mick P. Couper, and Frederick G. Conrad. 2004. "Spacing, Position, and Order---Interpretive Heuristics for Visual Features of Survey Questions.” Public Opinion Quarterly 68(3):368-93. https://doi.org/10.1093/poq/nfh035

Traczyk, Jakub and Tomasz Zaleskiewicz. 2016. "Implicit Attitudes toward Risk: The Construction and Validation of the Measurement Method." Journal of Risk Research 19(5):632-44. https://doi.org/10.1080/13669877.2014.1003957

Tversky, Amos and Daniel Kahneman. 1992. "Advances in Prospect Theory: Cumulative Representation of Uncertainty." Journal of Risk and Uncertainty 5(4):297-323. https://doi.org/10.1007/BF00122574

Tyszka, Tadeusz and Artur Domurat. 2004. “Czy Istnieje Ogólna Skłonność Jednostki Do Ryzyka?" Decyzje (2):85-104.

Van de Mortel, Thea F. 2008. "Faking it: social desirability response bias in self-report research." Australian Journal of Advanced Nursing, The 25(4): 40.

Warneryd, K. E. 1996. "Risk Attitudes and Risky Behavior." Journal of Economic Psychology 17(6):749-70. https://doi.org/10.1016/S0167-4870(96)00034-7 
Weber, Elke U. and Ann-Renée Blais. 2006. “ADomain-Specific Risk-Taking(DOSPERT) Scale for Adult Populations." Judgement and Decision Making 1(1):33-47.

Zheng, Congcong and Radmila Prislin. 2012. "Beyond Risk Propensity - the Influence of Evaluation Period and Information Relevance on Risk Taking Behavior." Academy of Entrepreneurship Journal 18(1):1-19.

Zuckerman, Marvin. 1994. Behavioral Expressions and Biosocial Bases of Sensation Seeking. Cambridge University Press. Retrieved January 7, 2018 (https:// books.google.pl/books/about/Behavioral_Expressions_and_Biosocial_Bas. html?id=ApiyY8LX5fAC\&redir_esc=y).

(Aklin et al. 2005; Baird and Thomas 1985; Bettman 1973; Börjesson et al. 2015; Coppola 2014; Densberger 2014; Golik 2016; Harrison et al. 2005; Horcajo et al. 2014; Hung and Tangpong 2010; Jackson et al. 1972; Kaldana and Ruzzier 2012; Koloba 2014; Lejuez et al. 2002; Meertens and Lion 2008; Mishra and Lalumière 2011; Schuman et al. 1981; Schwarz and Hippler 1995; Schwarz, Hippler, and Noelle-Neumann 1992; Sharma et al. 2009; SITKIN and WEINGART 1995; Slovic 1964; Strack 1992; Tourangeau, Couper, and Conrad 2004; Traczyk and Zaleskiewicz 2016; Tversky and Kahneman 1992; Tyszka and Domurat 2004; Van de Mortel 2008; Warneryd 1996; Weber and Blais 2006; Zheng and Prislin 2012; Zuckerman 1994); Blais, and Betz 2002) 
